\title{
The influence of adolescent age at first union on physical intimate partner violence and fertility in Uganda: A path analysis
}

\author{
C Odimegwu, $\mathrm{PhD}$; S Frade, MA

\begin{abstract}
Demography and Population Studies Programme, Schools of Social Sciences and Public Health, University of the Witwatersrand, Johannesburg, South Africa
\end{abstract}

Corresponding author: S Frade (sasha.frade@wits.ac.za)

\begin{abstract}
Background. Uganda has a high fertility rate, high levels of intimate partner violence (IPV) and also very young ages at first union. Experiencing IPV has previously been shown to increase fertility rates. Entering marriage at a later age has been shown to decrease fertility rates in some countries. Given that a large proportion of Ugandan women are married by the end of adolescence, marital age may be a key proximate determinant of fertility in Uganda.

Objective. To examine the effect of age at first union on fertility, via the intermediate effect of physical IPV, among Ugandan women of reproductive age.

Methods. Data from the 2011 Ugandan Demographic and Health Survey were used to create an integrated path model to investigate the effects of age at first union on fertility. Known factors that influence fertility were included in the model. The interaction with age at first union in increasing fertility differentials, via the intermediate effect of physical IPV, was assessed.

Results. Results show that women who are preadolescent or adolescent at first union have a higher likelihood of experiencing IPV, indicated by both direct and indirect pathways that work via known intermediate and proximate factors. Furthermore, age at first union increases fertility, expressed as the number of children born to a woman, via a direct interaction.

Conclusion. Most Ugandan women enter their first union during adolescence ( $<19$ years), which exposes them to a higher risk of IPV and a longer period of childbearing, thereby increasing fertility rates.
\end{abstract}

S Afr J Child Health 2018;12(2 Suppl 1):S51-S56. DOI:10.7196/SAJCH.2018.v12i2.1498

Uganda has one of the highest fertility rates in the world, ${ }^{[1]}$ high levels of intimate partner violence (IPV) ${ }^{[2,3]}$ and also very young ages at first union. ${ }^{[4]}$ In 2016, the total fertility rate in Uganda was 5.4 , which currently is the fifth highest in the world (preceded only by Niger, Burundi, Mali and Somalia). ${ }^{[5]}$ Uganda also has the second highest age-specific fertility rate. ${ }^{[1]}$ Although fertility rates have generally decreased, adolescent fertility rates have increased. ${ }^{[3]}$ Despite studies to investigate the reasons for the consistently high fertility rates in the country, neither research nor government initiatives have succeeded in decreasing these rates over the past two decades. ${ }^{[3,6]}$

Experiencing IPV has been shown to increase fertility rates in two sub-Saharan African countries and those authors concluded that IPV remains an unexplained intermediate factor of fertility. ${ }^{[7]}$ However, that study did not focus specifically on the situation in Uganda, nor did it investigate the potential pathways whereby sociodemographic (proximate) factors may influence the known intermediate factors, including physical IPV, in increasing fertility rates.

Two proximate factors known to influence fertility rates are place of residence and education level of the mother, and although the pathway along which these factors influence fertility has been much investigated and debated, the factors themselves are not well understood. However, it is known that women of higher educational status and women living in urban areas have lower fertility rates than women in rural areas or with a lower educational level. ${ }^{[8-10]}$

Wodon et al. ${ }^{[4]}$ have found that in countries where family planning programmes have not led to a decrease in fertility rates, entering into marriage at a later age has been the most effective way of decreasing fertility rates. In Uganda, a large proportion of women are married by the time they reach the end of their adolescent years. ${ }^{[4]}$ Young age at first union - whether through legal marriage or simply by cohabitation - could therefore be a proximate factor contributing to the high fertility rate in Uganda. It has also been found that low education levels and little bargaining power - both of which are repercussions of a young marital age - were key factors in explaining high levels of IPV in the certain countries. ${ }^{[4]}$

Therefore, this study aimed to examine the effect of age at first union on fertility, with experience of physical IPV considered as an intermediate effect.

\section{Method}

Path analysis as performed in this study was based on data from the 2011 Ugandan Demographic and Health Survey (UDHS). The UDHS used a two-stage sampling process to select participants. In the first stage, 404 enumeration areas were selected from clusters identified in the 2009/2010 National Household Survey. In the second stage, households were purposely selected in each cluster. Adult women of reproductive age (15 - 49 years) who had been included in the domestic violence module of the 2011 UDHS were included in this study, resulting in a total sample size of 2056.

In this study, cumulative fertility was measured as the number of children ever born (CEB). CEB is determined by asking a woman how many children she has borne in her lifetime. ${ }^{[1]}$

Previous experience of physical IPV is hypothesised to be a mediated effect of age at first union. In the UDHS, information on previous experience of physical IPV, which is hypothesised to be a mediated effect of age at first union, was separated into less severe and more severe forms. However, for the purposes of this study, the severities were combined. 
Physical acts of IPV included whether a woman has ever been pushed, shaken, slapped, punched, kicked/dragged or strangled/ burned, had something thrown at her or her hair twisted/pulled, or has been threatened with a knife/gun/another weapon by a husband/ partner. Interviewers of the DHS ensured privacy of all participants. When privacy could not be assured, the interview did not continue. If a woman had never experienced physical IPV, the response was coded as 'No' (0), whereas responses from those who had previously experienced physical IPV were coded as 'Yes' (1).

Age at first union was defined as the age at which a woman first entered a marital union or began to cohabitate with a long-term partner (non-legal marriage). Age at first union was categorised as: $<15$ years (1); $15-19$ years (2), and $>20$ years (3). The latter was considered the open-age category, as women who first entered a union after the age of 25 represented only $5 \%$ of the sample.

Proximate and intermediate factors found to affect fertility in other contexts were selected and included in the analysis. The following intermediate effects were included:

- planning of most recent pregnancy - pregnancy not planned (0); pregnancy planned (1)

- current contraceptive use - no contraception (1); traditional method (2); modern method (3)

- previous pregnancy terminated - no (0); yes (1).

The following proximate factors were included:

- highest education level attained - none (0); primary (1); secondary (2); higher than secondary (3)

- place of residence - urban (1); rural (2)

- involvement in household decisions - woman solely or partially responsible for decisions (1); woman not involved in decisionmaking process (2).

Scoring with regard to decision-making was based on whether a woman was involved in deciding on (a) visiting friends and family, (b) large household purchases and (c) decisions about her own healthcare, as included in the UDHS. Women who were not involved in any one of these decisions were categorised as not involved in the decision-making process, while those who were involved in one or more of these decisions were categorised as solely or partially responsible for decisions.

The variance inflation factor was used to check for multicollinearity between factors. None of the factors showed multicollinearity.

The hypothesised relationship between age at first union, physical IPV and fertility was investigated using path analysis. This approach uses a path diagram to show the hypothesised causal relationships in a model. ${ }^{[1-14]}$ The causal relationships can be direct (go directly from one variable to another) or indirect (mediated by one or more variables). ${ }^{[1,12]}$ Path coefficients indicate the relative strength of the respective effects on the outcome (fertility). ${ }^{[11,12,14]}$ Path analysis follows the same assumptions as least square regression, as all relationships are assumed to be inear, additive and causal. ${ }^{[9]}$

Variables are coded as follows in the path diagram:

- $v 201$ denotes CEB

- agecatcohab denotes age at first union

- v106 denotes highest education level

- $v 025$ denotes place of residence

- $v 228$ denotes whether a previous pregnancy had been terminated

- allphys2 denotes physical IPV

- currcontmeth denotes current contraceptive method used

- unintpreg denotes whether a pregnancy had been planned

- HhdDM denotes a woman's involvement in household decisions.

\section{Results}

The mean CEB for Ugandan women of reproductive age is 3.5. However, the mean CEB among women who were younger than 15 years at first union is 5.77 (Fig. 1). The mean CEB for women aged 15 - 19 years and $\geq 20$ years at first union is 4.03 and 3.51 , respectively.

Of the women who first legally married or cohabitated before the age of 15 or between 15 and 19 years, almost half (47\%) had experienced physical IPV (Fig. 2). In contrast, of the women who entered into marriage or cohabitation by the age of 20 or older, $26 \%$ had experienced physical IPV.

The path diagram (Fig. 3) for the hypothesised integrated model shows the relationships between age at first union, physical IPV and fertility, together with the known proximate and intermediate factors. The diagram shows that each proximate and intermediate factor has a direct relationship with CEB. However, the indirect relationships that link the effects of age at first union, physical IPV and fertility have an additive effect, which increases or decreases the CEB. Therefore, it is the relationship between and among these factors, and how they affect the relationship between age at first union and fertility, mediated by physical IPV, which is of interest. This relationship is influenced by other factors that either directly or indirectly affect the pathway from age at first union, experience of physical IPV and fertility.

Table 1 shows the path coefficients for each hypothesised direct and indirect pathway, as well as the total effect. The path coefficients estimate the magnitude of the hypothesised causal relationships. There are 74 pathways in the model, of which 42 were significant according to the $t$-test $(p<0.05$ at a 95\% confidence interval). Removal of the non-significant paths did not alter the results of the



Fig. 1. Percentage distribution of fertility according to age at first union.

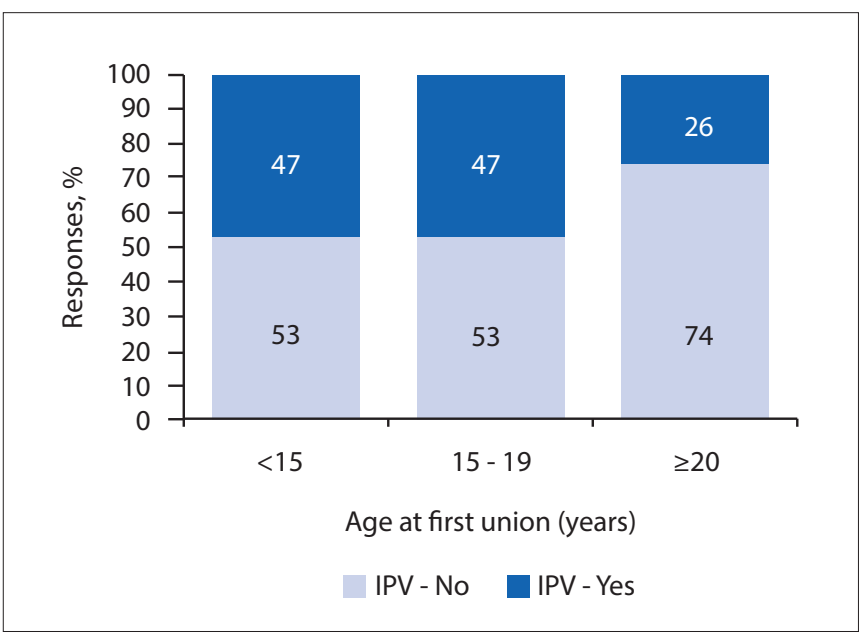

Fig. 2. Percentage of Ugandan women who have previously experienced physical $I P V$ distributed according to age at first union. (IPV = intimate partner violence.) 




Fig. 3. Pathway diagram showing the direct and indirect pathways and pathway coefficients from age at first union and physical IPV to fertility, controlled by other key endogenous and exogenous factors. $(\varepsilon=$ error term.)

$t$-test, but it did change the fit statistics. This indicates that including the non-significant factors created a model of better fit than when excluding them.

The total effect of age at first union on CEB is negative, whereas the total effect of physical IPV is positive. In other words, women who are older at first union have fewer children than those who are younger than 20 at first union. Furthermore, women who enter first union during the preadolescent or adolescent years are more likely to experience physical IPV. Age at first union also has a significant negative effect on physical IPV. As such, the older the woman at first union, the lower the likelihood that she will experience physical IPV. The total negative effect of age at first union on fertility is 0.26 , whereas experience of physical IPV has a total positive effect of 0.32 . In addition, the total negative effect of age at first union on physical IPV is 0.08 .

Age at first union had both a significant direct and indirect effect on planning of a previous pregnancy. In addition, age at first union had a significant direct effect on current contraceptive method and a significant indirect effect on having had a pregnancy terminated. All these factors had significant total effects on CEB: a negative total effect caused by planning of a previous pregnancy and a positive effect caused by having had a pregnancy terminated and current contraceptive use. Furthermore, two of these known intermediate factors of fertility, namely planning of a previous pregnancy and having had a pregnancy terminated, were significantly affected by physical IPV. Physical IPV affected planning of a previous pregnancy negatively, while it affected having had a pregnancy terminated positively.

\section{Discussion}

Compared with women who entered their first union before 20 years of age, those who entered their first union after 20 years of age had fewer children and fewer had experienced physical IPV. Although limited studies have investigated adolescent age at union as a risk factor for experiencing physical IPV, some studies have found that women in developed countries in the northern hemisphere who marry in their early 20 s are more at risk of experiencing abuse than those who marry at a later age. ${ }^{[15]}$ Given that women in Uganda generally enter first union at a young age, with very few entering their first union beyond their early 20s, Ugandan women may be at risk of experiencing physical IPV. Furthermore, women who enter their first union before or during adolescence may face a dual disadvantage, as they have an increased likelihood not only of experiencing physical IPV but also of having more children than women who enter first union after the age of 20. In a study that examined how age at first union is used to safeguard and protect women in times and environments fraught with conflict and violence, the authors concluded that this may, in fact, increase fertility during these times. ${ }^{[16]}$ Given that parts of Uganda have experienced social unrest in the past, this could, in part, explain the pathway relationships found in this study. ${ }^{[17]}$

According to the path analysis, the relationship between age at first union, fertility and likelihood of physical IPV is amplified by the interaction of direct and indirect effects with other key factors. Given that many of the women who enter first union before the end of adolescence are not able to complete their education, ${ }^{[18]}$ age at first union further exacerbates the observed effect as a higher level of education decreases both the incidence of physical IPV and fertility rates.

Women who have not completed their education and who have entered unions at a young age also have a lower likelihood of being involved in key household decisions - a proxy used for women's empowerment. ${ }^{[19]}$ A lack of women's empowerment, in turn, impacts not only on their opportunity to complete school but also on their ability to negotiate the use of contraceptives and ideal number of children. As such, decisions that would limit or halt childbearing, such as contraceptive use and terminating a pregnancy, are likely not taken by the woman or may even be forced on her through physical IPV, which could lead to unintended or mistimed pregnancies. ${ }^{[20]}$

Studies have shown that women who experience physical IPV suffer from a number of reproductive health outcomes, including low contraceptive use, stillbirths, miscarriages and unwanted pregnancies. ${ }^{[20]}$ According to our results, this relationship is also evident in the Ugandan context. However, our study expands the body of knowledge by considering also the proximate factors that influence the likelihood of experiencing physical IPV and, as a result, increase fertility rates. This finding adds to the understanding of pathways in which the proximate factors influence fertility through age at first union by showing the interaction of the known proximate factors and the mediating effect of physical IPV.

Providing contraception to girls at the beginning of their reproductive life cycle may not only delay childbearing but also increase quality of life and a woman's future income earning potential. ${ }^{[21]}$ However, in a society that values large families ${ }^{[22]}$ and a context in which physical IPV levels remain high, ${ }^{[17]}$ as is the case in Uganda, this outcome is unlikely. Therefore, education and advocating for smaller families alone will not decrease fertility rates. Such actions must be integrated into programmes that work with communities and households to decrease physical IPV levels and discourage preadolescent and adolescent unions.

\section{Study limitations}

One limitation of the study was that it was not possible to distinguish between stillbirths, miscarriages and abortions from the data entered under 'termination of pregnancies' in the 2011 UDHS, as abortions are illegal in Uganda. Another limitation relates to the cross-sectional nature of the data 
Table 1. Path coefficients of the hypothesised model of the influence of age at first union and physical IPV on fertility, controlling for selected exogenous and endogenous factors

\begin{tabular}{|c|c|c|c|c|}
\hline & Coefficient & $\begin{array}{l}\text { Standardised } \\
\text { coefficient }\end{array}$ & $p$-value & $95 \% \mathrm{CI}$ \\
\hline \multicolumn{5}{|l|}{ Direct effects } \\
\hline \multicolumn{5}{|c|}{ Planning of a previous pregnancy $<^{*}$} \\
\hline currcontmeth & -0.08 & 0.02 & 0.00 & $-0.12--0.05$ \\
\hline allphys 2 & -0.08 & 0.03 & 0.01 & $-0.14--0.02$ \\
\hline agecatcohab & 0.03 & 0.02 & 0.11 & $-0.01-0.07$ \\
\hline \multicolumn{5}{|c|}{ Current contraceptive method $\leftarrow$} \\
\hline HhdDM & -0.03 & 0.06 & 0.67 & $-0.15-0.10$ \\
\hline allphys2 & -0.05 & 0.05 & 0.30 & $-0.15-0.05$ \\
\hline agecatcohab & -0.08 & 0.04 & 0.02 & $-0.16--0.01$ \\
\hline$v 025$ & -0.42 & 0.06 & 0.00 & $-0.55--0.29$ \\
\hline$v 106$ & 0.18 & 0.04 & 0.00 & $0.11-0.26$ \\
\hline \multicolumn{5}{|c|}{ Household decision-making $\leftarrow$} \\
\hline agecatcohab & 0.02 & 0.02 & 0.20 & $-0.01-0.05$ \\
\hline$v 106$ & -0.01 & 0.02 & 0.36 & $-0.05-0.02$ \\
\hline \multicolumn{5}{|l|}{ Physical IPV $\leftarrow$} \\
\hline$H h d D M$ & 0.01 & 0.04 & 0.84 & $-0.07-0.08$ \\
\hline agecatcohab & -0.08 & 0.02 & 0.00 & $-0.12--0.04$ \\
\hline v025 & 0.08 & 0.04 & 0.04 & $0.00-0.15$ \\
\hline$v 106$ & -0.08 & 0.02 & 0.00 & $-0.12--0.03$ \\
\hline \multicolumn{5}{|c|}{ Ever had a pregnancy terminated $\leftarrow$} \\
\hline allphys2 & 0.08 & 0.03 & 0.00 & $0.03-0.13$ \\
\hline$v 106$ & 0.00 & 0.02 & 0.77 & $-0.03-0.04$ \\
\hline \multicolumn{5}{|c|}{ Children ever born $\leftarrow$} \\
\hline unintpreg & -0.98 & 0.14 & 0.00 & $-1.25--0.70$ \\
\hline currcontmeth & 0.26 & 0.08 & 0.00 & $0.09-0.42$ \\
\hline$H h d D M$ & 0.52 & 0.18 & 0.00 & $0.17-0.88$ \\
\hline allphys2 & 0.20 & 0.15 & 0.16 & $-0.08-0.49$ \\
\hline$v 228$ & 0.74 & 0.17 & 0.00 & $0.42-1.07$ \\
\hline agecatcohab & -0.19 & 0.10 & 0.08 & $-0.39-0.02$ \\
\hline$v 025$ & 0.61 & 0.19 & 0.00 & $0.24-0.97$ \\
\hline$v 106$ & -1.06 & 0.11 & 0.00 & $-1.27--0.86$ \\
\hline \multicolumn{5}{|l|}{ Indirect effects } \\
\hline \multicolumn{5}{|c|}{ Planning of a previous pregnancy $\leftarrow$} \\
\hline$H h d D M$ & 0.00 & 0.01 & 0.78 & $-0.01-0.01$ \\
\hline allphys2 & 0.00 & 0.00 & 0.30 & $-0.00-0.01$ \\
\hline agecatcohab & 0.01 & 0.00 & 0.00 & $0.00-0.02$ \\
\hline v025 & 0.03 & 0.01 & 0.00 & $0.01-0.05$ \\
\hline$v 106$ & -0.01 & 0.01 & 0.06 & $-0.02-0.00$ \\
\hline \multicolumn{5}{|c|}{ Current contraceptive method $\leftarrow$} \\
\hline$H h d D M$ & -0.00 & 0.00 & 0.84 & $-0.00-0.00$ \\
\hline agecatcohab & 0.00 & 0.00 & 0.41 & $-0.01-0.01$ \\
\hline$v 025$ & -0.00 & 0.00 & 0.35 & $-0.01-0.00$ \\
\hline$v 106$ & 0.00 & 0.00 & 0.29 & $-0.00-0.01$ \\
\hline \multicolumn{5}{|l|}{ Physical IPV $\leftarrow$} \\
\hline agecatcohab & 0.00 & 0.00 & 0.84 & $-0.00-0.00$ \\
\hline$v 106$ & -0.00 & 0.00 & 0.85 & $-0.00-0.00$ \\
\hline \multicolumn{5}{|c|}{ Ever had a pregnancy terminated $\leftarrow$} \\
\hline$H h d D M$ & 0.00 & 0.00 & 0.84 & $-0.01-0.01$ \\
\hline agecatcohab & -0.01 & 0.00 & 0.02 & $-0.01--0.00$ \\
\hline v025 & 0.01 & 0.00 & 0.08 & $-0.00-0.01$ \\
\hline \multicolumn{5}{|c|}{ Children ever born $\leftarrow$} \\
\hline currcontmeth & 0.08 & 0.02 & 0.00 & $0.05-0.11$ \\
\hline$H h d D M$ & -0.01 & 0.02 & 0.78 & $-0.06-0.04$ \\
\hline
\end{tabular}


Table 1. (continued) Path coefficients of the hypothesised model of the influence of age at first union and physical IPV on fertility, controlling for selected exogenous and endogenous factors

\begin{tabular}{|c|c|c|c|c|}
\hline & Coefficient & $\begin{array}{l}\text { Standardised } \\
\text { coefficient }\end{array}$ & $p$-value & $95 \% \mathrm{CI}$ \\
\hline allphys2 & 0.12 & 0.04 & 0.00 & $0.04-0.19$ \\
\hline agecatcohab & -0.08 & 0.03 & 0.01 & $-0.13--0.02$ \\
\hline$v 025$ & -0.12 & 0.05 & 0.01 & $-0.21--0.03$ \\
\hline$v 106$ & 0.03 & 0.03 & 0.24 & $-0.02-0.09$ \\
\hline \multicolumn{5}{|l|}{ Total effects } \\
\hline \multicolumn{5}{|c|}{ Planning of a previous pregnancy $\leftarrow$} \\
\hline currcontmeth & -0.08 & 0.02 & 0.00 & $-0.12--0.05$ \\
\hline HhdDM & 0.00 & 0.01 & 0.78 & $-0.01-0.01$ \\
\hline allphys2 & -0.07 & 0.03 & 0.02 & $-0.13--0.01$ \\
\hline agecatcohab & 0.05 & 0.02 & 0.03 & $0.01-0.09$ \\
\hline$v 025$ & 0.03 & 0.01 & 0.00 & $0.01-0.05$ \\
\hline$v 106$ & -0.01 & 0.01 & 0.06 & $-0.02-0.00$ \\
\hline \multicolumn{5}{|c|}{ Current contraceptive method $\leftarrow$} \\
\hline HhdDM & -0.03 & 0.06 & 0.67 & $-0.15-0.10$ \\
\hline allphys2 & -0.05 & 0.05 & 0.30 & $-0.15-0.05$ \\
\hline agecatcohab & -0.08 & 0.04 & 0.03 & $-0.15--0.01$ \\
\hline$v 025$ & -0.43 & 0.06 & 0.00 & $-0.55--0.30$ \\
\hline$v 106$ & 0.19 & 0.04 & 0.00 & $0.12-0.26$ \\
\hline \multicolumn{5}{|c|}{ Household decision-making $\leftarrow$} \\
\hline agecatcohab & 0.02 & 0.02 & 0.20 & $-0.01-0.05$ \\
\hline$v 106$ & -0.01 & 0.02 & 0.36 & $-0.05-0.02$ \\
\hline \multicolumn{5}{|l|}{ Physical IPV $\leftarrow$} \\
\hline$H h d D M$ & 0.01 & 0.04 & 0.84 & $-0.07-0.08$ \\
\hline agecatcohab & -0.08 & 0.02 & 0.00 & $-0.12--0.04$ \\
\hline v025 & 0.08 & 0.04 & 0.04 & $0.00-0.15$ \\
\hline$v 106$ & -0.08 & 0.02 & 0.00 & $-0.12--0.03$ \\
\hline \multicolumn{5}{|c|}{ Ever had a pregnancy terminated $\leftarrow$} \\
\hline$H h d D M$ & 0.00 & 0.00 & 0.84 & $-0.01-0.01$ \\
\hline allphys2 & 0.08 & 0.03 & 0.00 & $0.03-0.13$ \\
\hline agecatcohab & -0.01 & 0.00 & 0.02 & $-0.01--0.00$ \\
\hline$v 025$ & 0.01 & 0.00 & 0.08 & $-0.00-0.01$ \\
\hline$v 106$ & -0.00 & 0.02 & 0.95 & $-0.03-0.03$ \\
\hline \multicolumn{5}{|l|}{ Children ever born $\leftarrow$} \\
\hline unintpreg & -0.98 & 0.14 & 0.00 & $-1.25--0.70$ \\
\hline currcontmeth & 0.34 & 0.09 & 0.00 & $0.17-0.51$ \\
\hline$H h d D M$ & 0.52 & 0.18 & 0.01 & $0.16-0.88$ \\
\hline allphys2 & 0.32 & 0.15 & 0.03 & $0.02-0.62$ \\
\hline$v 228$ & 0.74 & 0.17 & 0.00 & $0.42-1.07$ \\
\hline agecatcohab & -0.26 & 0.11 & 0.01 & $-0.47--0.05$ \\
\hline$v 025$ & 0.49 & 0.18 & 0.01 & $0.13-0.85$ \\
\hline$v 106$ & -1.03 & 0.11 & 0.00 & $-1.24--0.82$ \\
\hline \multicolumn{5}{|l|}{ Model fit statistics } \\
\hline \multicolumn{5}{|l|}{ Likelihood ratio } \\
\hline Model v. Saturated & & 6.64 & & \\
\hline \multicolumn{5}{|l|}{ Population error } \\
\hline RMSEA & & 0.00 & & \\
\hline \multicolumn{5}{|l|}{ Information criteria } \\
\hline AIC & & 19411.38 & BIC & 19637.97 \\
\hline \multicolumn{5}{|l|}{ Baseline comparison } \\
\hline CFI & & 1.00 & TLI & 1.02 \\
\hline \multicolumn{5}{|l|}{ Size of residuals } \\
\hline SRMR & & 0.01 & $\mathrm{CD}$ & 0.24 \\
\hline
\end{tabular}


in relation to the causal scheme of pathway analysis. In the absence of longitudinal data, causal pathways cannot be assured and would need to be investigated further based on data in which the actual time of physical IPV in relation to a pregnancy can be assessed. This may provide further insight into the short- and long-term effects of physical IPV on fertility.

\section{Conclusion}

Uganda experiences high levels of first union at adolescence, high levels of physical IPV and one of the highest fertility rates in the world. Most Ugandan women enter their first union during adolescence $(<19$ years), which exposes them to a higher risk of IPV and a longer period of childbearing, resulting in a high fertility rate. It is imperative that policies and programmes do not attempt to address either of these challenges in isolation, given their relationship with each other and with other proximate factors that influence fertility.

Further research needs to examine whether the relationship between age at first union and fertility, mediated by physical IPV, is also seen in other contexts with continued high or stalling fertility rates. In addition, research that includes differentiated variables for stillbirths, miscarriages and abortions is required to assess the magnitude of each of these factors in the integrated model introduced here. Also, an investigation into how age at first union affects the form or level of severity of physical IPV is required to assess the effect of these factors on the number of children a woman has. Although the number of children born to a woman did not appear to be strongly related to household decision-making, it is possible that this variable was indicative of the intricacies of women's (lack of) negotiating power in the home and with regard to their reproductive needs and desires. We recommend this as an area to be further explored.

Acknowledgements. The support of the DST-NRF Centre of Excellence in Human Development towards this research/activity is hereby acknowledged. Opinions expressed and conclusions arrived at, are those of the author and are not necessarily to be attributed to the CoE in Human Development The authors gratefully acknowledge the National Institute of Humanities and Social Sciences (NIHSS) and the Demography and Population Studies Programme at the University of the Witwatersrand for contributing to the funding and support of this paper, which forms part of a doctoral thesis.

Author contributions. SF and CO were both involved in conceptualising the study, data analysis and interpretation, and preparing the manuscript. Both authors gave final approval of the version to be published and agree to be accountable for all aspects of the work.

Funding. None.

Conflicts of interest. None.

1. Geoba. Uganda. http://www.geoba.se/country.php?cc=UG (accessed 26 January 2018).

2. ActionAid. Violence is a fact of life for the women of Uganda. http://www. actionaid.org/violenceagainstwomen (accessed 26 January 2018).
3. Uganda Bureau of Statistics (UBOS) and ICF. Uganda Demographic and Health Survey 2016: Key indicators report. Kampala and Rockville: UBOS and ICF, 2017.

4. Wodon Q, Male C, Onagoruwa A, Savadogo A, Yedan A. The cost of not investing in girls in Uganda: Child marriage, early childbearing, low educational attainment for girls, and their impacts in Uganda. Washington DC: The World Bank, 2017. http://pubdocs.worldbank.org/ en/297781512451885312/The-Cost-of-Not-Investing-in-Girls-ChildMarriage-Early-Childbearing-Low-Educational-Attainment-for-Girls-andTheir-Impacts-in-Uganda.pdf (accessed 20 January 2018).

5. Statista Database. The 20 countries with the highest fertility rates. https:// www.statista.com/statistics/262884/countries-with-the-highest-fertilityrates/ (accessed 26 January 2018).

6. Population Reference Bureau (PRB). Uganda: At the beginning of the demographic transition. https://www.prb.org/world-at-7-billion-part-2/ (accessed 26 January 2018)

7. Odimegwu C, Bamiwuye OS, Adedini SA. Gender-based violence as a new proximate determinant of fertility in sub-Saharan Africa. S Afr J Demogr 2015;16(1):87-121.

8. Martin TC. Women's education and fertility: Results from 26 demographic and health surveys. Stud Family Plann 1995;26(4):187-202. https://doi. org $/ 10.2307 / 2137845$

9. Dow TE. Fertility and family planning in Africa. J Mod Afr Stud 1970;8(03):445-457.

10. Sibanda A, Woubalem Z, Hogan DP, Lindstrom DP. The proximate determinants of the decline to below replacement fertility in Addis Ababa, Ethiopia. Stud Family Plann 2003;34(1):1-7. https://doi.org/10.1111/j.17284465.2003.00001.x

11. Lleras C. Path analysis. Enc Soc Meas 2005;3:25-30. https://doi.org/10.1016/ b0-12-369398-5/00483-7

12. Loebner H, Driver ED. Differential fertility in Central India: A path analysis. Demography 1973;10(3):329-350. https://doi.org/10.2307/2060843

13. Chi PS, Harris RJ. An integrated model of fertility: A multivariate analysis of fertility differentials in Colombia. Can Stud Popul 1979;6:111-125. https:// doi.org/10.25336/p63600

14. Islam TM. Influence of socio-demographic variables on fertility in Bangladesh: Application of path model analysis. Pakistan J Soc Sci 2009;6(5):313-320.

15. O'Leary KD, Tintle N, Bromet E. Risk factors for physical violence against partners in the US. Psychol Violence 2014;4(1):65-77. https://doi.org/10.1037/ a0034537

16. Neal S, Stone N, Ingham R. The impact of armed conflict on adolescent transitions: A systematic review of quantitative research on age of sexual debut, first marriage and first birth in young women under the age of 20 years. BMC Public Health 2016;16(1):225. https://doi.org/10.1186/s12889016-2868-5

17. Kinyanda E, Weiss HA, Mungherera M, et al. Intimate partner violence as seen in post-conflict eastern Uganda: Prevalence, risk factors and mental health consequences. BMC Int Health Hum Rights 2016;16(1):5. https://doi. org/10.1186/s12914-016-0079-x

18. Walker JA. Early marriage in Africa - Trends, harmful effects and interventions. Afr J Reprod Health 2012;16(2):231-240.

19. Stromquist NP. Women's empowerment and education: Linking knowledge to transformative action. Eur J Educ 2015;50(3):307-324. https://doi. org/10.1111/ejed.12137

20. Pallitto CC, Campbell JC, O'Campo P. Is intimate partner violence associated with unintended pregnancy? A review of the literature. Trauma Violence Abuse 2005;6(3):217-235. https://doi.org/10.1177/1524838005277441

21. Klepinger D, Lundberg S, Plotnick R. How does adolescent fertility affect the human capital and wages of young women? J Hum Resour 1999;34(3):421448. https://doi.org/10.2307/146375

22. Adams MK, Salazar E, Lundgren R. Tell them you are planning for the future: Gender norms and family planning among adolescents in northern Uganda. Int J Gynaecol Obstet 2013;123(Suppl 1):e7-e10. https://doi.org/10.1016/j. ijgo.2013.07.004

Accepted 31 May 2018. 